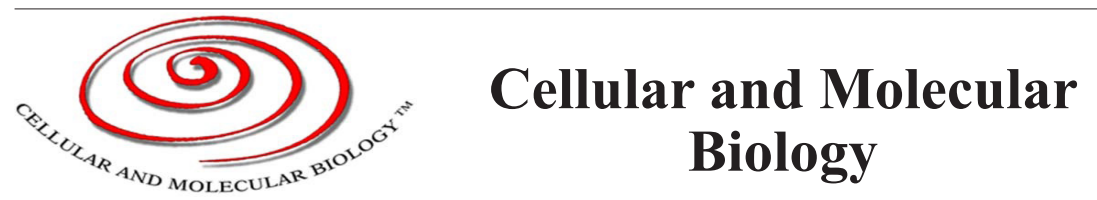

Chen et al. Cell. Mol. Biol.2016, 62 (13): 54-61

ISSN: $1165-158 \mathrm{X}$

Original Research

\title{
Pivotal role of glutathione depletion in eNOS uncoupling of LPS-Treated HUVECs
}

doi: $10.14715 / \mathrm{cmb} / 2016.62 .13 .10$

\author{
L. Chen, E. Liu, D. Cao, S. Li, C. Xiao, M. Xiong, Q. Kou*
}

Department of ICU, The Sixth Affiliated Hospital of Sun Yet-Sen University, Guangzhou, China

\begin{abstract}
The present study investigated the relationship between uncoupling of endothelial nitric oxide synthase (eNOS) and vascular endothelial cell (VEC) oxidative stress (OS) during sepsis and the role of eNOS glutathionylation in eNOS uncoupling of septic VECs. Human umbilical vein endothelial cells (HUVECs) cultured in vitro (EA.hy269 cell line) were incubated with Dulbecco's modified Eagle's medium (DMEM) (normal control group), lipopolysaccharide (LPS) (sepsis group), 1,3-bis(2-chloroethyl)-1-nitrosourea (BCNU) (glutathionylation group), and LPS+ dithiothreitol (DTT) (deglutathionylation sepsis group). As result, compared with the DMEM group, malondialdehyde (MDA) level and uncoupling eNOS activity significantly increased in the LPS and BCNU groups. However, in the LPS + DTT group, only the NO level increased. Compared with the LPS group, MDA level, NO concentration, and normal functional eNOS activity significantly decreased, and uncoupling eNOS activity significantly increased in the BCNU group. In the LPS + DTT group, MDA level and uncoupling eNOS activity significantly decreased, and NO concentration and normal functional eNOS activity significantly increased. During sepsis, the main mechanism for VEC OS was eNOS uncoupling mediated by eNOS glutathionylation.
\end{abstract}

Key words: Endothelial nitric oxide synthase, glutathionylation, synthesis, uncoupling, vascular endothelial cells.

\section{Introduction}

Sepsis refers to the systemic inflammatory response syndrome caused by infections; further development can cause very severe conditions including septic shock, severe sepsis, multiple organ dysfunction syndromes, and even death $(1,2)$. In recent years, the mortality rate of sepsis in the young population has decreased (3) because of the implementation of Surviving Sepsis Campaign: International Guidelines for Management of Severe Sepsis and Septic Shock (4-6). However, the statistical analysis from intensive care units have indicated that the mortality rates of sepsis and septic shock are still as high as $30 \%$ and $60 \%$, respectively $(7,8)$.

The pathogenesis mechanism of sepsis is very complicated. The major pathophysiological processes include cytokine storm, inflammatory waterfall-like reaction, enteral bacterial translocation, intestinal-derived endotoxin, interplay between coagulation and inflammation systems, oxidative stress (OS), immune cell apoptosis, microcirculation, and mitochondrial dysfunction(9-11). Of these, vascular endothelial cell (VEC) dysfunction plays a major role in the pathogenesis for sepsis. During chronic inflammation, the VEC dysfunction mainly shows endothelial nitric oxide (NO) synthase (eNOS) dysfunction. As we know that NO, as the most important diastolic regulation factor, plays an important role in the regulation of VECs. At present a lot of researches have confirmed that the decreased NO concentration is the most important reason to aggravate vascular endothelial dysfunction in the pathological process of chronic inflammatory vascular disease (12). Malondialdehyde (MDA), as a product of lipid oxidative damage, is a classic biomarker to evaluate the degree of oxidative stress damage (13). Typically, eNOS exists in the form of dimer, and electron transfer and NO synthesis are closely related, so it can catalyze the synthesis of NO. However, in pathological conditions, the dimer dissociates into monomers which can not complete the chain reaction in the process of electron transfer, and emergence of uncoupling electron is likely to be abnormally passed to $\mathrm{O}_{2}$, generating superoxide anion $\left(\mathrm{O}_{2}^{-}\right)$. In the end, eNOS results in the production of superoxide instead of NO (14). It results in decreased bioavailability of $\mathrm{NO}$ and increased OS, further causing or aggravating endothelium relaxation dysfunction, which is called eNOS uncoupling (15).

The mechanism of eNOS uncoupling includes (16, 17): (1) lack of NO-generating substrate, L-arginine (L-Arg); (2) insufficient supply of important cofactor, tetrahydrobiopterin $(\mathrm{BH} 4)$, generated from $\mathrm{NO}$; and (3) changed structure of eNOS induced by OS, such as decreased activity induced by eNOS glutathionylation. Recently, Chen et al. (18) found that the site of eNOS glutathionylation was Cys 689 and Cys 908. Meanwhile, it was also proved that glutathione reductase inhibitor, 1,3-bis(2-chloroethyl)-1-nitrosourea (BCNU) or oxidized glutathione could result in eNOS glutathionylation. 2-mercaptoethanol or dithiothreitol (DTT) could reversibly reduce the glutathionylated eNOS.

In the study on sepsis, Huet et al. reported using in vitro culture $(19,20)$ of human umbilical vein endothelial cell (HUVEC) and incubation of serum from sepsis patients, the reduced glutathione concentration in VECs played important roles in cell damage caused by ROS during sepsis. It was found that not only ROS generation mediated by sepsis serum, but also the death rate were related to the decrease in intracellular glutathione

Received April 22, 2016; Accepted November 20, 2016; Published November 30, 2016

\footnotetext{
* Corresponding author: Qiuye Kou, Department of ICU, The Sixth Affiliated Hospital of Sun Yet-Sen University, Guangzhou 510655, China. Email: kouqiuye@126.com
}

Copyright: (C) 2016 by the C.M.B. Association. All rights reserved. 
Table 1. Group of EA.hy926 cell line.

\begin{tabular}{|c|c|c|}
\hline Group & Abbreviation & Treatment factor \\
\hline Control group & DMEM & DMEM high-glucose (25 mmol/L) culture medium (Gibco, USA, 592) \\
\hline Sepsis group & LPS & $\begin{array}{l}1 \mathrm{mg} / \mathrm{L} \text { LPS (Sigma, USA) }(22)+ \\
\text { DMEM high-glucose }(25 \mathrm{mmol} / \mathrm{L}) \text { culture medium (Gibco, USA) }\end{array}$ \\
\hline Glutathione depletion group & BCNU & $\begin{array}{l}5 \mathrm{mg} / \mathrm{L} \text { BCNU (Sigma, USA) }+ \\
\text { DMEM high-glucose }(25 \mathrm{mmol} / \mathrm{L}) \text { culture medium (Gibco, USA) }\end{array}$ \\
\hline Deglutathionylation sepsis group & LPS + DTT & $\begin{array}{l}1 \mathrm{mg} / \mathrm{L} \mathrm{LPS}+2 \mathrm{mmol} / \mathrm{L} \text { DTT (Sigma, USA) + DMEM high-glucose } \\
(25 \mathrm{mmol} / \mathrm{L}) \text { culture medium (Gibco, USA) }\end{array}$ \\
\hline
\end{tabular}

level.

What is the relationship between VEC OS of sepsis and eNOS uncoupling? What is the mechanism for eNOS uncoupling during sepsis? Based on the cell model, the relationship between sepsis VEC OS and eNOS uncoupling and the possible mechanism for eNOS uncoupling were explored, which could provide evidence for treating OS of sepsis at an early stage.

\section{Materials and Methods}

\section{Endothelial cells}

HUVECs (EA.hy269) were obtained from Shanghai Cell Bank of Chinese Academy of Sciences (Shanghai, China) and cultured as previously described (21).

After EA.hy926 cell line was cultured to $60 \%-70 \%$, the cells were cultured in Dulbecco's modified Eagle's medium (DMEM) without serum for $12 \mathrm{~h}$, washed with phosphate-buffered saline (PBS) twice, treated according to Table 1 , and cultured for $12 \mathrm{~h}$.

\section{Cell viability and apoptosis assays}

HUVECs $\left(2 \times 10^{4} /\right.$ well $)$ in each group were seeded in 96-well plates (Costar, Corning, USA) and incubated for $12 \mathrm{~h}$. The cell viability was determined from the reduction of 3-(4,5-Dimethylthiazol-2-yl)-2,5-diphenyltetrazolium bromide(MTT) to formazan. The absorbance at $550 \mathrm{~nm}$ was recorded in each well using an enzymelinked immunosorbent assay (ELISA) microplate reader. The results were expressed as $\%$ of viable cells \pm standard error of means relative to cells in the culture medium alone (defined as $100 \%$ viability). Cell viability was monitored in all cases using the crystal violet assay (23).

\section{OS levels}

The activities of malondialdehyde (MDA) were measured in HUVECs after $12 \mathrm{~h}$ of exposure in each group. MDA levels were measured with a commercially available kit (Ransod, Randox Laboratories, Montpellier, France) based on the method of thiobarbituric acid colorimetry.

The activities of NO were measured in HUVECs after $12 \mathrm{~h}$ of exposure in each group. NO levels were measured with a commercially available kit (Ransod, Randox Laboratories) based on the method of nitrate reductase activity determination.

The activities of superoxide dismutase (SOD) were measured in HUVECs after $12 \mathrm{~h}$ of exposure in each group. SOD activities (T-SOD) were measured with a commercially available kit (Ransod, Randox Laborato- ries) based on the method developed by McCord and Fridovich (24).

\section{Intracellular eNOS levels}

The intracellular difference in eNOS levels were assessed after $12 \mathrm{~h}$ of exposure in each group. Total eNOS activities (teNOS) were measured with a commercially available kit (Ransod, Randox Laboratories) based on ELISA (25). Normal functional eNOS activities (feNOS) were measured by the conversion of L-arginine to NO using a nitric oxide synthase assay kit (Beyotime Institute of Biotechnology, Nanjing, China) as previously described (26). Uncoupling eNOS activity (ueNOS) was calculated as the difference between teNOS and feNOS activities.

\section{Detection for BH4 and L-Arg level}

After incubation for $12 \mathrm{~h}$, the EA.hy269 cells were washed with $2 \mathrm{~mL}$ of cold PBS three times and cleaned. Then, cold extracting solution $(50 \mathrm{mmol} / \mathrm{L}$ Tris$\mathrm{HCl}, \mathrm{pH} 7.4 ; 1 \mathrm{mmol} / \mathrm{L}$ EDTA) was added. The cells were subjected to repetitive freeze-thaw cycles three times (low temperature $-80^{\circ} \mathrm{C}$, high temperature $40^{\circ} \mathrm{C}$ ), and centrifuged at $15,000 \mathrm{rpm}$ for $10 \mathrm{~min}$ under $4^{\circ} \mathrm{C}$. The supernatant was extracted, and the protein concentration in the supernatant $(10 \mu \mathrm{L})$ was detected using a bicinchoninic acid(BCA) kit (Beyotime Biotechnology, Nanjing, China). The supernatant $(200 \mu \mathrm{L})$ was taken, added to reaction buffer $(1.8 \mathrm{~mL})$, and then poured onto a piece of absorbent filter paper (Matsumoto Institute of Life Science, Kanazawa, Japan). All samples were stored at $-20^{\circ} \mathrm{C}$, and within 1 week, they were sent to the Laboratory of Inborn Errors of Metabolism (Sixth Affiliated Hospital of Sun Yat-Sen University) for metabolite profile analysis.

A clean urine sample $(2 \mathrm{~mL})$ was collected from each participant within the first $24 \mathrm{~h}$ after birth, using a urine collection bag. The urine was poured either into a drying tube or onto a piece of absorbent filter paper (Matsumoto Institute of Life Science). All samples were stored at $-20^{\circ} \mathrm{C}$, and within 1 week, they were sent to the laboratory for metabolite profile analysis.

A JMS-Q1000GC UltraQuad (Akishima, Tokyo, Japan) gas chromatograph/mass spectrometer was used for $\mathrm{GC} / \mathrm{MS}$ measurement. Aliquots $(1 \mu \mathrm{L})$ of derived extracts were injected into the apparatus using an automatic injection mode. The separation was carried out using an Ultra ALLOY metal capillary column UA530M-0.25F (Koriyama, Fukushima, Japan). The oven temperature was programmed to increase $17^{\circ} \mathrm{C} / \mathrm{min}$ from $60^{\circ} \mathrm{C}$ to $220^{\circ} \mathrm{C}$, hold at $220^{\circ} \mathrm{C}$ for $2 \mathrm{~min}$, and then 
increase $15^{\circ} \mathrm{C} / \mathrm{min}$ from $220^{\circ} \mathrm{C}$ to $325^{\circ} \mathrm{C}$, with a final holding at $325^{\circ} \mathrm{C}$ for $10 \mathrm{~min}$. The temperatures of the injection port, ion source, and transfer line were $260^{\circ} \mathrm{C}$, $200^{\circ} \mathrm{C}$, and $220^{\circ} \mathrm{C}$, respectively. Electron ionization mass spectra were obtained by repetitive scanning at 2.5 cycles/s, from $m / z 50$ to $m / z 650$. Helium gas was used as the carrier at a flow rate of $1 \mathrm{~mL} / \mathrm{min}$.

The gas chromatography/mass spectrometry $(\mathrm{GC} /$ MS) data were analyzed and interpreted based on the JEOL GC-MS analysis system (MILS, Kanazawa, Japan) and National Institute of Standards and Technology database, and the positive cases were reviewed by experts from both sides. The laboratory routinely conducts internal quality control and participates in external quality assessments organized by the European Research Network for Evaluation and Improvement of Screening, Diagnosis and Treatment of Inherited Disorders of Metabolism.

\section{Statistical analysis}

Statistical analyses were conducted using the SPSS software (version 13.0; SPSS, IL, USA). Normally distributed variables were presented as mean \pm standard deviation, and the differences between the two groups were analyzed using the $t$ test. A $P$ value $<0.05$ was considered statistically significant. The comparisons of average values among groups were analyzed using analysis of variance, and the comparisons between two average values with statistical significance were tested. Those with homogeneity of variance were tested by least significant difference, and those without homogeneity of variance were tested by Games-Howell test. $P$ less than 0.05 was considered statistically significant.

\section{Results}

\section{eNOS uncoupling cell model}

BCNU (concentrations 0.1, 0.5, 2, 5, 20, and 40 $\mathrm{mg} / \mathrm{L}$ ) was used to culture the EA.hy269 cell line for $12 \mathrm{~h}$, and the MTT method was used to test cell viability. Figure 1A shows that as the BCNU concentration increased, the cell viability gradually decreased. The group treated with 20 and $40 \mathrm{mg} / \mathrm{L}$ showed a significant difference compared with other groups $(P<0.05)$. Figure $1 \mathrm{~B}$ shows that the degree of eNOS uncoupling was increased with the concentration of BCNU. The group treated with 5, 20 and $40 \mathrm{mg} / \mathrm{L}$ showed no difference ( $P$ $>0.05)$.

By optimizing, $5 \mathrm{mg} / \mathrm{L}$ BCNU was chosen to build the cell model. Uncoupling eNOS levels at 6,12, and $24 \mathrm{~h}$ were detected. As showed in Figure 2, compared with the DMEM group, the uncoupling eNOS level in the BCNU group significantly increased $(P<0.05)$, and showed a significant difference $12 \mathrm{~h}$ after incubation $(P$ $<0.001)$. The desirable eNOS uncoupling VECs model was built using $5 \mathrm{mg} / \mathrm{L} \mathrm{BCNU}$ after 12-h incubation.

\section{Cell model of sepsis OS}

The EA.hy269 cell line incubated with LPS is the common sepsis VECs model. In the present study, 1 $\mathrm{mg} / \mathrm{L}$ LPS was used to incubate the EA.hy269 cell line and OS levels at 6,12, and $24 \mathrm{~h}$ were detected. As illustrated in Figure 3A-B, compared with the DMEM culture medium group, the ROS level in the LPS group
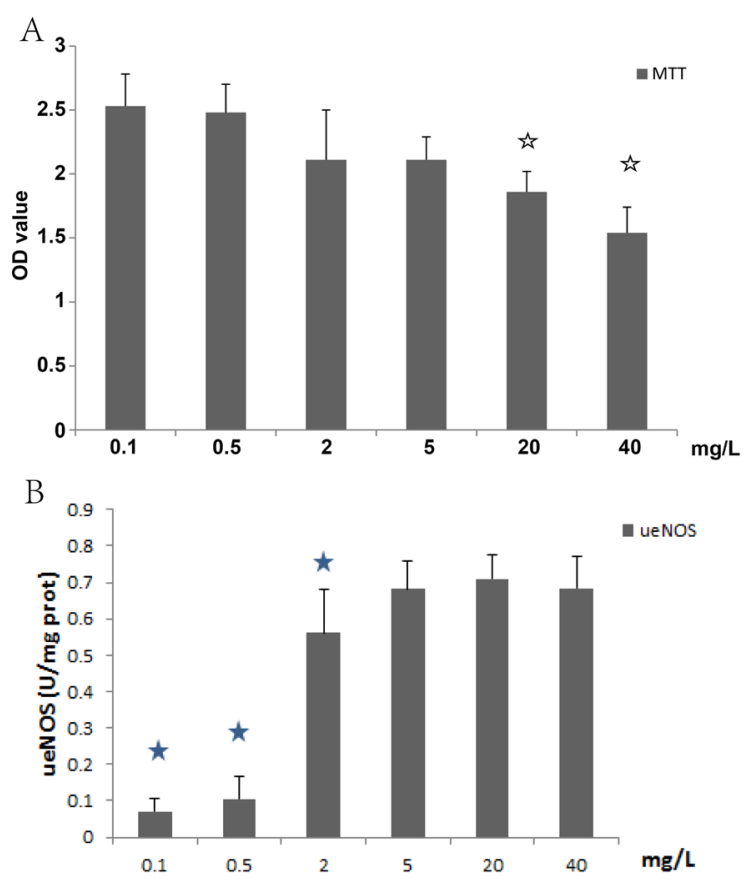

Figure 1. Influence of different $\mathrm{BCNU}$ concentrations on EA.hy926 cell viability and ueNOS level. The EA.hy926 cell line was cultured with different concentrations $(0.1,0.5,2,5,20$, and $40 \mathrm{mg} / \mathrm{L}$ ) of BCNU for $12 \mathrm{~h}$. MTT was used to detect cell viability, the total eNOS and eNOS activity was detected, the difference was the uncoupled eNOS activity expressed as ueNOS $(25,26)$, and the results were expressed as mean \pm standard deviation (SD). The experiment was repeated three times. Figure A shows that as the $\mathrm{BCNU}$ concentration increased, the cell viability gradually decreased. When the BCNU concentration was higher than $20 \mathrm{mg} / \mathrm{L}$, the cell viability significantly decreased $(P<0.05)$. is Represents $P<0.05$ compared with other groups. Figure B shows that the degree of eNOS uncoupling was increased with the concentration of BCNU. The group treated with 5,20 and $40 \mathrm{mg} / \mathrm{L}$ showed no difference $(P>0.05)$. $\star$ Represents $P<0.05$ compared with the $20 \mathrm{mg} / \mathrm{L}$ group.

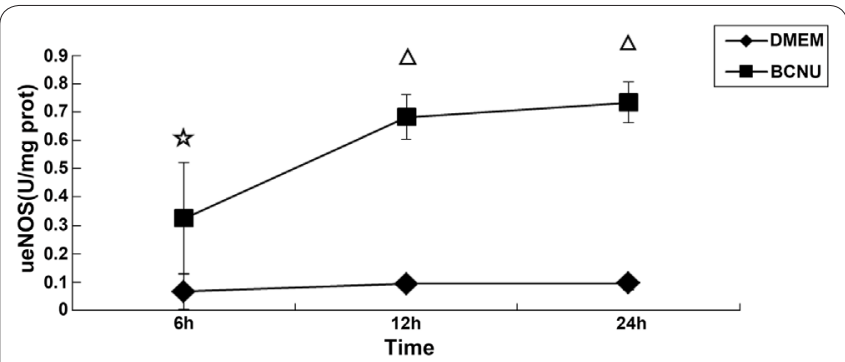

Figure 2. Changing trend for uncoupling eNOS. EA.hy269 was cultured with BCNU $(5 \mathrm{mg} / \mathrm{L})$, and the total eNOS and eNOS activity was detected at 6,12 , and $24 \mathrm{~h}$. The difference was the uncoupled eNOS activity expressed as ueNOS $(25,26)$. At the same time point, EA.hy269 cultured with DMEM was used as the control group, and the result was expressed as mean $\pm \mathrm{SD}$. The experiment was repeated three times. The results showed that compared with the DMEM group, the ueNOS activity at each time point significantly increased in the BCNU group $(P<0.05)$. is Represents $P<$ 0.05 , and $\Delta$ represents $P<0.001$.

significantly increased $(P<0.001)$, and the NO concentration in the culture medium decreased with time $(P<$ $0.05)$. It suggested that sepsis VEC OS model could be built by incubating the EA.hy269 cell line with LPS for $12 \mathrm{~h}$. 


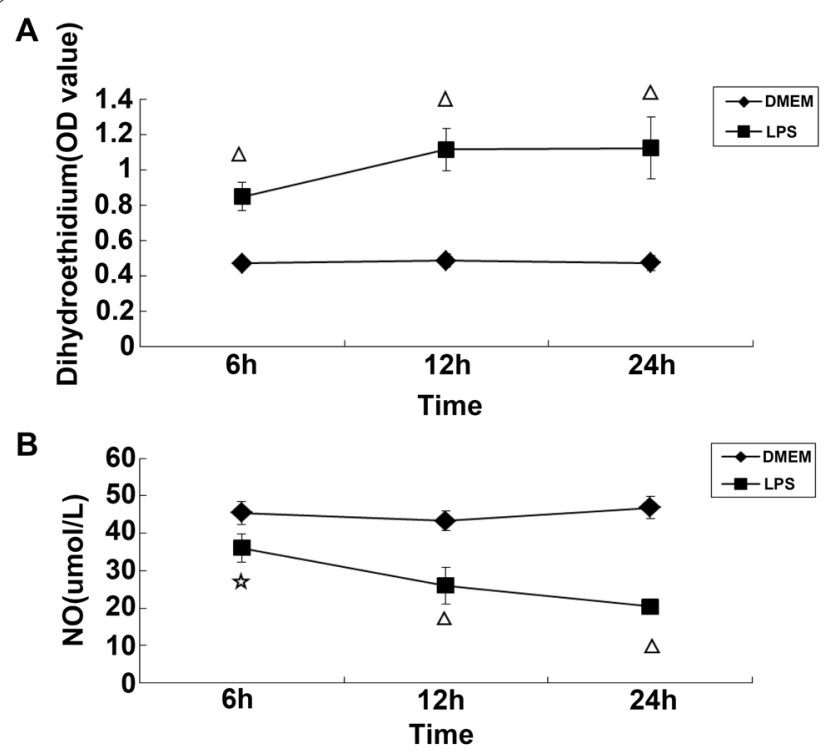

Figure 3. Changing trend for ROS and NO. LPS ( $1 \mathrm{mg} / \mathrm{L})$ was used to culture EA.hy269, and intracellular ROS levels and NO levels in the culture medium were detected by the dihydroethidium fluorescence probe method at 6, 12, and $24 \mathrm{~h}$. Figure A showed that compared with the DMEM group, ROS levels in the LPS group significantly increased from $6 \mathrm{~h}$ to $12 \mathrm{~h}(\mathrm{P}<0.001)$. Figure $\mathrm{B}$ showed that compared with the DMEM group, NO levels at each time point in the LPS group significantly increased $(\mathrm{P}<0.05)$. The result was expressed as mean $\pm \mathrm{SD}$, and corrected by MTT. The experiment was repeated three times. is Represents $\mathrm{P}<0.05$, and $\Delta$ Represents $\mathrm{P}<0.001$.

\section{Cell morphology and cell viability}

EA.hy269 cells were given LPS ( $1 \mathrm{mg} / \mathrm{L}), \mathrm{BCNU}(5$ $\mathrm{mg} / \mathrm{L})$, LPS $(1 \mathrm{mg} / \mathrm{L})+$ DTT $(2 \mathrm{mmol} / \mathrm{L})$, and DMEM high glucose $(25 \mathrm{mmol} / \mathrm{L})$ for $12 \mathrm{~h}$. The morphology of all the groups was similar. MTT was used to detect cell viability and repeated three times. Considering the detected optical density value as unit, the cell activity in each group was as follows: LPS group, 2.22; BCNU group, 2.11, DTT+LPS group, 2.36; and DMEM group, 2.53. No statistical difference was found among the cell activities in the groups $(P>0.05)$, as shown in Figure 4.

\section{Relationship between eNOS uncoupling and sepsis OS}

As shown in Figure 5 and Table 2, in the eNOS uncoupling cell model, compared with the DMEM group, MDA level and T-SOD activity in the BCNU group significantly increased $(P<0.05)$, the ROS level detected by dihydroethidium fluorescence probe also significantly increased $(P<0.05)$, but the NO concentration significantly decreased $(P<0.05)$. As illustrated in Figure 6, in the sepsis VEC OS model, compared with the DMEM group, intracellular uncoupling eNOS activity significantly increased in the LPS group $(P<0.05)$.

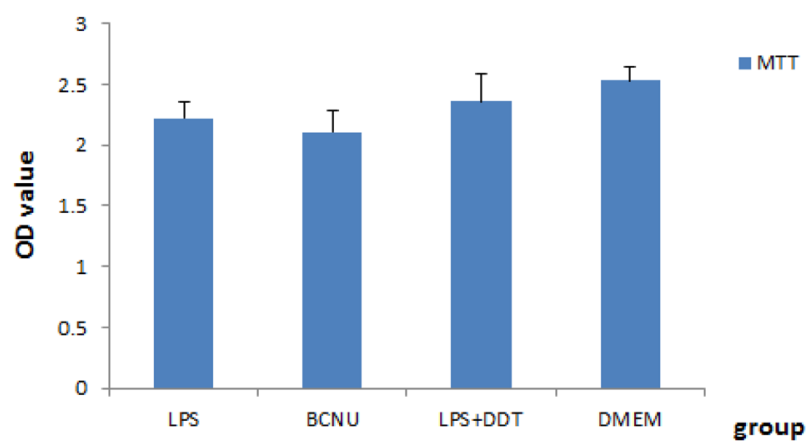

Figure 4. Comparisons of EA.hy926 cell viability in each group. EA.hy926 cell line was stimulated by LPS (1 mg/L), BCNU ( $5 \mathrm{mg} /$ $\mathrm{mL})$, LPS $(1 \mathrm{mg} / \mathrm{L})+\mathrm{DTT}(2 \mathrm{mmol} / \mathrm{L})$, and DMEM high glucose $(25 \mathrm{mmol} / \mathrm{L}$ ) for $12 \mathrm{~h}$. MTT was used to detect cell viability, and no significant difference was found among the groups $(P>0.05)$. The experiment was repeated three times.
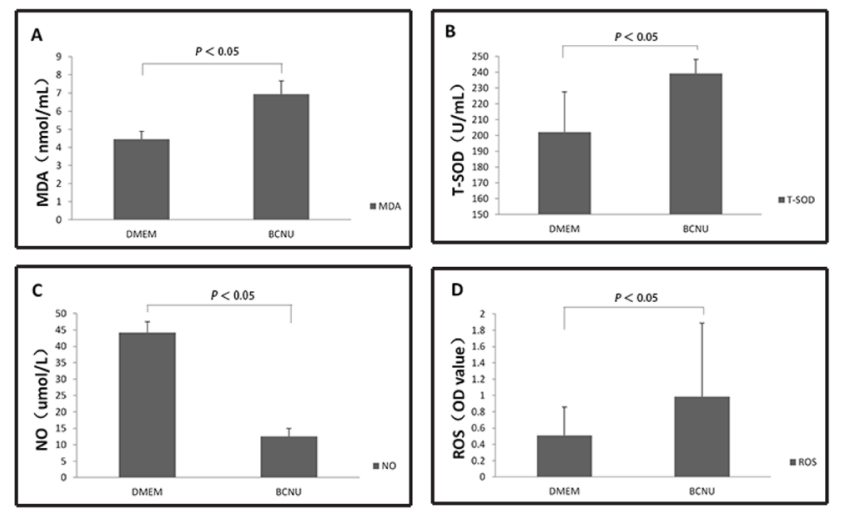

Figure 5. Oxidative stress condition at $12 \mathrm{~h}$ in the eNOS uncoupling cell model. EA.hy269 was cultured with BCNU (5 mg/L) and DMEM for $12 \mathrm{~h}$, and MDA level, T-SOD activity, NO concentration and ROS level was detected. The results showed that in the eNOS uncoupling cell model, compared with the DMEM group, MDA level, T-SOD activity and the ROS level in the BCNU group significantly increased $(\mathrm{P}<0.05)$, but the NO concentration significantly decreased $(\mathrm{P}<0.05)$. The result was expressed as mean \pm $\mathrm{SD}$, and repeated three times.

\section{Mechanism for sepsis uncoupling}

As shown in Figure 7, $12 \mathrm{~h}$ after incubating the EA.hy 269 cell line with LPS, intracellular BH4 and LArg levels did not change significantly compared with the DMEM group $(P>0.05)$.

As shown in Figure 8 and Table 3, compared with the DMEM group, at $12 \mathrm{~h}$ after incubation, the MDA levels in the LPS and BCNU groups both significantly increased $(P<0.01)$, and NO levels significantly decreased $(P<0.01)$. However, no significant difference was found in the T-SOD activity ( $P>0.05)$, suggesting that the OS in sepsis model and OS in the eNOS uncoupling model both could result in VECs dysfunction. Nevertheless, compared with the BCNU group, the MDA level in the LPS group more significantly increased $(P$

Table 2. Oxidative stress condition at $12 \mathrm{~h}$ in the eNOS uncoupling cell model ( $m e a n \pm \mathrm{SD}, n=3$ ).

\begin{tabular}{ccccc}
\hline Group & MDA $(\mathbf{n m o l} / \mathbf{m L})$ & T-SOD $(\mathbf{U} / \mathbf{m L})$ & NO $(\boldsymbol{\mu m o l} / \mathbf{L})$ & ROS $($ OD value $)$ \\
\hline DMEM & $4.457 \pm 0.431$ & $202.16 \pm 25.41$ & $44.15 \pm 3.39$ & $0.510 \pm 0.346$ \\
BCNU & $6.941 \pm 0.713^{\star}$ & $239.28 \pm 8.84^{\star}$ & $12.56 \pm 2.45^{\star}$ & $0.987 \pm 0.902^{\star}$ \\
\hline
\end{tabular}

Note: ${ }^{\star}$ Compared with the DMEM group, $P<0.05$. 
Table 3. Comparison between sepsis and eNOS glutathionylation (mean $\pm \mathrm{SD}, n=3$ ).

\begin{tabular}{llllll}
\hline & LPS & BCNU & DMEM & $\boldsymbol{F}$ & $\boldsymbol{P}$ \\
\hline MDA & $8.286 \pm 2.058^{\star \Delta}$ & $6.328 \pm 1.299^{\star}$ & $4.414 \pm 0.682$ & 10.561 & 0.001 \\
T-SOD & $220.15 \pm 26.08$ & $223.14 \pm 28.58$ & $203.68 \pm 20.15$ & 1.038 & 0.378 \\
NO & $31.29 \pm 7.32^{\star \Delta}$ & $15.81 \pm 7.01^{\star}$ & $43.73 \pm 2.74$ & 31.946 & 0.001 \\
teNOS & $1.048 \pm 0.085$ & $0.952 \pm 0.155$ & $0.890 \pm 0.063$ & 3.285 & 0.066 \\
feNOS & $0.502 \pm 0.090^{\star \Delta}$ & $0.301 \pm 0.172^{\star}$ & $0.774 \pm 0.068$ & 23.934 & 0.001 \\
ueNOS & $0.547 \pm 0.107^{\star \Delta}$ & $0.651 \pm 0.078^{\star}$ & $0.116 \pm 0.035$ & 77.518 & 0.001
\end{tabular}

Note: teNOS, total eNOS; feNOS, normal functional eNOS; ueNOS, uncoupled eNOS. Unit: MDA (nmol/mL); T-SOD $(\mathrm{U} / \mathrm{mL}), \mathrm{NO}(\mu \mathrm{mol} / \mathrm{L}), \mathrm{NOS}\left(\mathrm{U} / \mathrm{mg}\right.$ prot). ${ }^{\star}$ compared with DMEM group, $P<0.05 ; \boldsymbol{\Delta}$ compared with BCNU group, $P<0.05$.

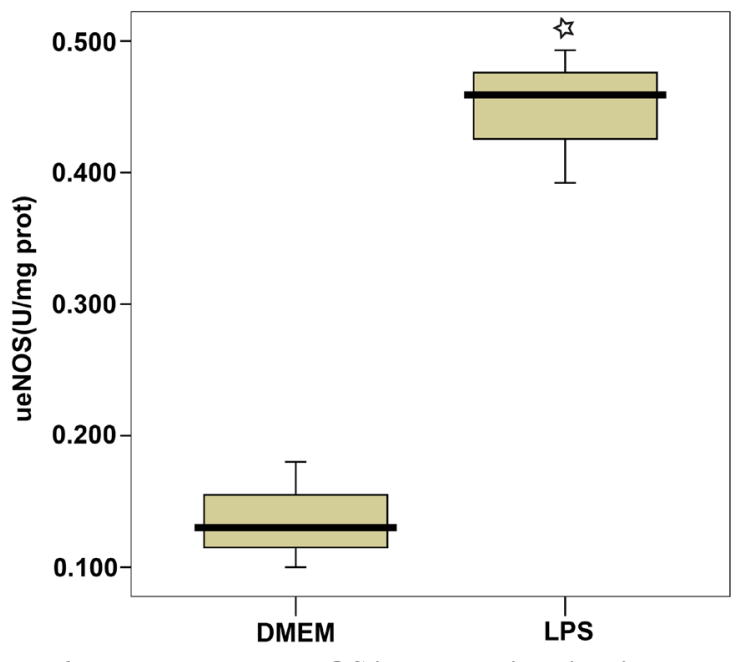

Figure 6. The uncoupled eNOS in the sepsis oxidative stress cell model. EA.hy269 was cultured with LPS (1 mg/L) for $12 \mathrm{~h}$, and the total eNOS and the eNOS activity was detected. The difference was the uncoupled eNOS activity expressed as ueNOS. The results showed that compared with the DMEM group, the intracellular uncoupling eNOS activity in the LPS group significantly increased $(P<0.05)$. The result was expressed as mean $\pm \mathrm{SD}$, and corrected by MTT. The experiment was repeated three times. is Represents $P<0.05$.

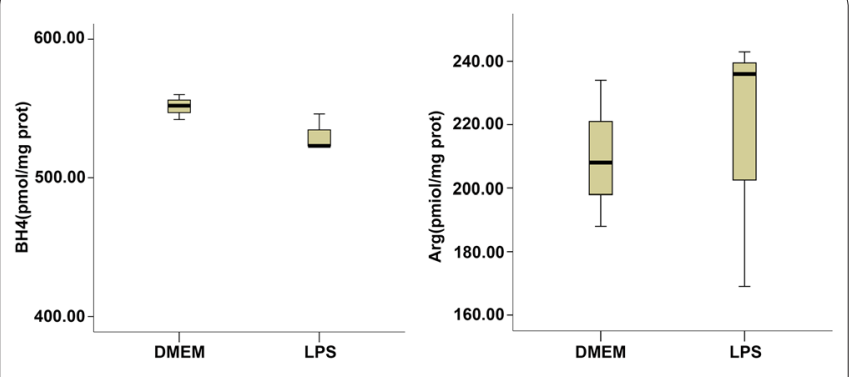

Figure 7. (A) $\mathbf{B H}_{4}$ level. After culturing EA.hy269 with LPS (1 $\mathrm{mg} / \mathrm{L}$ ) for $12 \mathrm{~h}$, the mass spectrum was used to detect the intracellular BH4 level. The result was corrected by MTT and expressed as mean. The experiment was repeated three times. The results showed that compared with the DMEM group, intracellular $\mathrm{BH}_{4}$ in the LPS group did not change significantly $(P>0.05)$. (B) L-Arg level. After culturing EA.hy 269 with LPS $(1 \mathrm{mg} / \mathrm{L})$ for $12 \mathrm{~h}$, the mass spectrum was used to detect the intracellular L-Arg level. The result was corrected by MTT and expressed as mean. The experiment was repeated three times. No significant difference was found in the intracellular L-Arg level in DMEM and LPS groups $(P>$ $0.05)$.

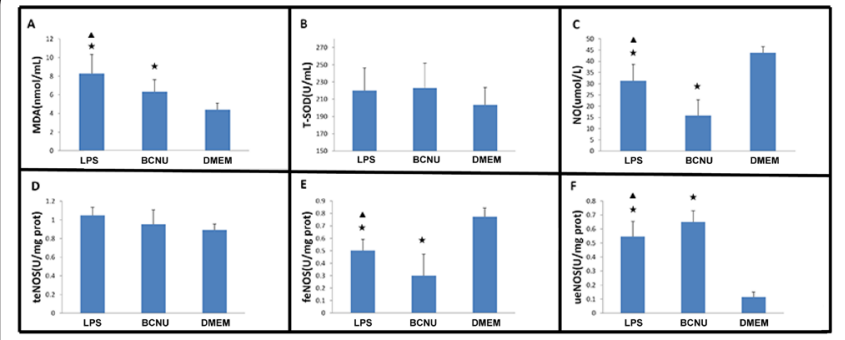

Figure 8. Comparison between sepsis and eNOS glutathionylation. EA.hy269 was cultured with LPS (1 mg/L), BCNU (5 $\mathrm{mg} / \mathrm{L}$ ) and DMEM for $12 \mathrm{~h}$. Then MDA level, T-SOD activity, NO concentration, the total eNOS and eNOS activity was detected, and the uncoupled eNOS activity was calculated. The experiment was repeated three times. $\star$ compared with DMEM group, $P<0.05$; compared with BCNU group, $P<0.05$.

$<0.01$ ), but T-SOD activity showed no significant difference $(P>0.05)$. It was suggested that the degree of VECs dysfunction induced by sepsis model was even more severe.

Meanwhile, compared with the DMEM group, intracellular total eNOS levels in the LPS and BCNU groups slightly increased, but with no statistical difference. Furthermore, normal functional eNOS (generating NO by catalytic reaction) levels significantly decreased and the uncoupling eNOS (generating ROS by catalytic reaction) level increased $(P<0.01)$, suggesting that glutathionylation of sepsis and eNOS both could result in eNOS uncoupling. Compared with the BCNU group, normal functional eNOS activity in the LPS group was higher $(P<0.01)$, the uncoupling eNOS activity was not as high as that in the BCNU group $(P<0.01)$, but the total eNOS activities in both the groups were equal, indicating that the degree of eNOS uncoupling caused by sepsis was not as good as single eNOS glutathionylation, as shown in Figure 8 Table 3.

As shown in Figure 9 and Table 4, compared with the DMEM group, the MDA level significantly increased in the LPS group $(P<0.01)$, the NO level significantly decreased $(P<0.01)$, and no significant difference was observed in the T-SOD activity $(\mathrm{P}>0.05)$. Also, the MDA level and T-SOD activity in the LPS + DTT group did not change significantly $(P>0.05)$ and the NO level significantly increased $(P<0.01)$. Compared with the LPS group, the MDA level in the LPS + DTT group significantly decreased, the NO concentration significant- 
Table 4. Comparison between sepsis and eNOS deglutathionylation (mean $\pm \mathrm{SD}, n=3$ ).

\begin{tabular}{|c|c|c|c|c|c|}
\hline & LPS & LPS + DTT & DMEM & $\boldsymbol{F}$ & $\boldsymbol{P}$ \\
\hline MDA & $8.286 \pm 2.058^{\star}$ & $5.046 \pm 1.114^{\wedge}$ & $4.414 \pm 0.682$ & 13.072 & 0.001 \\
\hline T-SOD & $220.15 \pm 26.08$ & $198.28 \pm 14.62$ & $203.68 \pm 20.15$ & 1.797 & 0.200 \\
\hline NO & $31.29 \pm 7.32^{\star}$ & $57.24 \pm 15.33^{\star \Delta}$ & $43.73 \pm 2.74$ & 10.244 & 0.002 \\
\hline teNOS & $1.048 \pm 0.085$ & $1.054 \pm 0.184$ & $0.890 \pm 0.063$ & 3.500 & 0.057 \\
\hline feNOS & $0.502 \pm 0.090^{\star}$ & $0.815 \pm 0.108^{\wedge}$ & $0.774 \pm 0.068$ & 21.291 & 0.001 \\
\hline ueNOS & $0.547 \pm 0.107^{\star}$ & $0.240 \pm 0.178^{\wedge}$ & $0.116 \pm 0.035$ & 19.921 & 0.001 \\
\hline
\end{tabular}

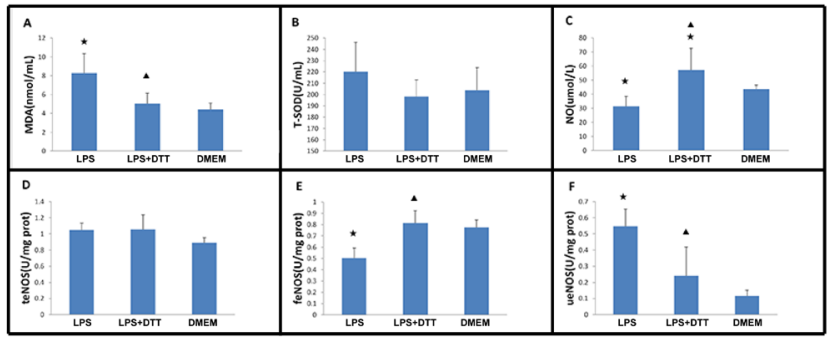

Figure 9. Comparison between sepsis and eNOS deglutathionylation. EA.hy269 was cultured with LPS (1 mg/L), BCNU (5 $\mathrm{mg} / \mathrm{L}$ ) and DMEM for $12 \mathrm{~h}$. Then MDA level, T-SOD activity, NO concentration, the total eNOS and eNOS activity was detected, and the uncoupled eNOS activity was calculated. The experiment was repeated three times. $\star$ compared with DMEM group, $P<0.05$; compared with BCNU group, $P<0.05$.

ly increased $(P<0.01)$, and the T-SOD activity showed no significant difference $(P>0.05)$. It was suggested that after glutathionylation modification of eNOS was removed by sepsis, the uncoupling of eNOS improved. Furthermore, the OS of cells was also significantly alleviated, VECs dysfunction was recovered, and even the NO level increased.

Compared with the DMEM group, the intracellular total eNOS level in the LPS group did not change significantly $(P>0.05)$, the normal functional eNOS level significantly decreased, and the uncoupling eNOS level increased $(P<0.01)$. However, total eNOS, normal functional eNOS, and uncoupling eNOS levels in the LPS + DTT group did not change significantly. Compared with the LPS group, the normal functional eNOS activity in the LPS + DTT group was higher $(P$ $<0.01)$ and the uncoupling eNOS activity significantly decreased $(P<0.01)$. It was suggested that the removal of glutathionylation modification of eNOS by sepsis could lead to the recovery of uncoupled eNOS activity, and decrease of uncoupled eNOS activity, as shown in Figure 9 and Table 4.

\section{Discussion}

This study explored the relationship between VECs dysfunction and OS in sepsis and the pivotal role of glutathione depletion in septic endothelial eNOS uncoupling. Using stable LPS-induced cell model and BCNUinduced cell model, the study demonstrated a mutually promoting, reciprocal relationship between OS and eNOS uncoupling, which was in line with the findings of previous studies $(15,27)$. Moreover, it was found that during sepsis, the glutathione level not only reflected the OS degree, but was significantly related with the prognosis of patients $(19,20)$. However, no significant differences were found in the concentrations of $\mathrm{BH}_{4}$ and L-Arg in the case of septic endothelial eNOS uncoupling; rather the rate of glutathione depletion was enhanced in acute sepsis.

A previous study confirmed the mechanisms for eNOS uncoupling in chronic inflammations (such as coronary artery atherosclerotic plaque and diabetes) (16, 17) as follows. (1) The insufficient $\mathrm{BH}_{4}$ level for eNOS uncoupling was the main reason. The decrease in the $\mathrm{BH}_{4}$ level was mainly caused by the decreased activity of dihydrofolate reductase and guanosine triphosphate cyclohydrolase I (GTPCH-I) during its biological synthesis (28). In the mice fed a high-salt diet, the decreased $\mathrm{BH}_{4}$ level caused eNOS uncoupling, and the increase in $\mathrm{O} 2$ - from eNOS caused a decrease in the vasodilation ability (29). Contrarily, the supply of $\mathrm{BH}_{4}$ could reverse eNOS dysfunction. For example, $\mathrm{BH}_{4}$ given to aorta separated from the hypertension model could decrease ROS derived from NOS. $\mathrm{BH}_{4}$ from ergogenic supplement could decrease eNOS uncoupling after myocardial infarction, decrease generation of peroxides, and slow down cardiac remodeling process (30). (2) The L-Arg level was insufficient to cause eNOS uncoupling. L-Arg not only was the substrate of eNOS, but also played a competitive effect with asymmetric dimethylarginine (ADMA), a kind of endogenous inhibitor. Under OS, the activity of protein-arginine methyl transferases (PRMT) increased and the activity of ADMA degrading enzyme, dimethylarginine dimethylaminohydrolase, decreased, leading to an increase in the ADMA level $(31,32)$. Furthermore, $24 \mathrm{~h}$ after stimulating HUVECs using thrombin or inflammatory factor, the expression level of arginase II in endothelial cells did not change, but its activity significantly increased, resulting in a decreased L-Arg level (33). (3) eNOS glutathionylation could result in eNOS uncoupling. Two conserved Cys (Cys689 and Cys908) in NOS family played a very important role in maintaining the normal activity of eNOS. Once they were glutathionylated, NOS generated $\mathrm{O}_{2}^{-}$by catalysis, and it could not be inhibited by L-NAME and removing $\mathrm{Ca}^{2+}$. Furthermore, BCNU could also cause 
eNOS glutathionylation and result in endothelial dysfunction (16). Moreover, eNOS glutathionylation in rats with spontaneous hypertension increased, and the endothelium dysfunction was also reversed by thiol-specific antagonists (such as dithiothreitol) (18).

The present study found that in the sepsis cell model based on EA.hy926 stimulated by LPS, the mechanism for eNOS uncoupling was different from that in chronic inflammations. Under sepsis, $\mathrm{BH}_{4}$ and L-Arg levels did not significantly decrease, suggesting that in the acute pathological processes such as sepsis, $\mathrm{BH}_{4}$ and L-Arg were not the main reason for eNOS uncoupling.

This study used methods with different testing principles for eNOS. ELISA could detect all the intracellular eNOS level. The fluorescence probe could only detect normal functional eNOS activity. The difference between them was mainly uncoupling eNOS, so ueNOS could be used for analysis. It has been reported that (18) BCNU and DTT were used to culture EA.hy926 for simulating eNOS glutathionylated and eNOS deglutathionylated cells, and the relationship between eNOS glutathionylation and eNOS uncoupling under sepsis was confirmed. In order to construct the stable eNOS uncoupling cell model in our study, we cultured the EA.hy 269 cell line for $12 \mathrm{~h}$ with $0.1,0.5,2,5,20$, and $40 \mathrm{mg} / \mathrm{L}$ BCNU respectively, and then the MTT method was used to test cell viability. As a result, the cell viabilities of EA.hy269 cell line incubated in 20 or $40 \mathrm{mg} / \mathrm{L}$ BCNU decreased significantly compared to in $0.1,0.5$, 2 or $5 \mathrm{mg} / \mathrm{L}$. However, the degree of eNOS uncoupling was increased with the concentration of BCNU. Accordingly, we chose $5 \mathrm{mg} / \mathrm{L}$ as the threshold of BCNU concentration, which is the concentration could be ensured both the viability of cells and the decoupling effect as far as possible. Furthermore, in our study compared with the DMEM group, the uncoupling eNOS level in the $5 \mathrm{mg} / \mathrm{L}$ BCNU group significantly increased $(\mathrm{P}<0.05)$, and showed a significant difference $12 \mathrm{~h}$ after incubation $(\mathrm{P}<0.001)$

In the present study, intracellular eNOS was divided into two types (NO generation and ROS generation), but besides the two types, a few nonfunctional eNOS were found as well. However, they were ignored due to their small levels. Hence, the detailed data might have been influenced, but the main conclusion remained the same. It is presumed that with the development of related technologies, the nonfunctional eNOS can be removed, resulting in enhanced reliability.

Although there are still some problems to be solved in our research, our research has shown that during sepsis simulated by LPS-treatment, the main mechanism for VEC OS is eNOS uncoupling mediated by eNOS glutathionylation.

\section{Acknowledgements}

Supported by Science and Technology Planning Project of Guangdong Province, 2013B021800123, and CHASE SUN Fund, China.

\section{References}

1. Shimaoka M, Park EJ. Advances in understanding sepsis. Eur J Anaesthesiol Suppl 2008; 42:146-53.

2. Levy MM, Fink MP, Marshall JC, Abraham E, Angus D, Cook
D, et al. $2001 \mathrm{SCCM} / \mathrm{ESICM} / \mathrm{ACCP} / \mathrm{ATS} / \mathrm{SIS}$ International Sepsis Definitions Conference. Intensive Care Med 2003; 29:530-8.

3. Kaukonen KM, Bailey M, Suzuki S, Pilcher D, Bellomo R. Mortality related to severe sepsis and septic shock among critically ill patients in Australia and New Zealand, 2000-2012. Jama 2014; 311:1308-16.

4. Dellinger RP, Carlet JM, Masur H, Gerlach H, Calandra T, Cohen J, et al. Surviving Sepsis Campaign guidelines for management of severe sepsis and septic shock. Crit Care Med 2004; 32:858-73.

5. Dellinger RP, Levy MM, Carlet JM, Bion J, Parker MM, Jaeschke R, et al. Surviving Sepsis Campaign: international guidelines for management of severe sepsis and septic shock: 2008. Crit Care Med 2008; 36:296-327.

6. Dellinger RP, Levy MM, Rhodes A, Annane D, Gerlach H, Opal $\mathrm{SM}$, et al. Surviving sepsis campaign: international guidelines for management of severe sepsis and septic shock: 2012. Crit Care Med 2013; 41:580-637.

7. Czura CJ. "Merinoff symposium 2010: sepsis"-speaking with one voice. Mol Med 2011; 17:2-3.

8. Moore LJ, McKinley BA, Turner KL, Todd SR, Sucher JF, Valdivia A, et al. The epidemiology of sepsis in general surgery patients. J Trauma 2011; 70:672-80.

9. Huet O, Dupic L, Harrois A, Duranteau J. Oxidative stress and endothelial dysfunction during sepsis. Front Biosci (Landmark Ed) 2011; 16:1986-95.

10. Rocha M, Herance R, Rovira S, Hernandez-Mijares A, Victor VM. Mitochondrial dysfunction and antioxidant therapy in sepsis. Infect Disord Drug Targets 2012; 12:161-78.

11. Boisrame-Helms J, Kremer H, Schini-Kerth V, Meziani F. Endothelial dysfunction in sepsis. Curr Vase Pharmacol 2013; 11:150-60. 12. Bian K, Murad F. Nitric oxide (NO)--biogeneration, regulation, and relevance to human diseases. Front Biosci 2003; 8:d264-78.

13. Chen J, Zeng L, Xia T, Li S, Yan T, Wu S, et al. Toward a biomarker of oxidative stress: a fluorescent probe for exogenous and endogenous malondialdehyde in living cells. Anal Chem 2015; 87:8052-6.

14. Forstermann U, Sessa WC. Nitric oxide synthases: regulation and function. Eur Heart J 2012; 33:829-37, 37a-37d.

15. Forstermann U, Munzel T. Endothelial nitric oxide synthase in vascular disease: from marvel to menace. Circulation 2006; 113:1708-14.

16. Zweier JL, Chen CA, Druhan LJ. S-glutathionylation reshapes our understanding of endothelial nitric oxide synthase uncoupling and nitric oxide/reactive oxygen species-mediated signaling. Antioxid Redox Signal 2011; 14:1769-75.

17. Roe ND, Ren J. Nitric oxide synthase uncoupling: a therapeutic target in cardiovascular diseases. Vascul Pharmacol 2012; 57:16872.

18. Chen CA, Wang TY, Varadharaj S, Reyes LA, Hemann C, Talukder MA, et al. S-glutathionylation uncouples eNOS and regulates its cellular and vascular function. Nature 2010; 468:1115-8.

19. Huet O, Cherreau C, Nicco C, Dupic L, Conti M, Borderie D, et al. Pivotal role of glutathione depletion in plasma-induced endothelial oxidative stress during sepsis. Crit Care Med 2008; 36:2328-34. 20. Huet O, Obata R, Aubron C, Spraul-Davit A, Charpentier J, Laplace $\mathrm{C}$, et al. Plasma-induced endothelial oxidative stress is related to the severity of septic shock. Crit Care Med 2007; 35:821-6.

21. Chanseaud Y, Garcia de la Pena-Lefebvre P, Guilpain P, Mahr A, Tamby MC, Uzan M, et al. IgM and IgG autoantibodies from microscopic polyangiitis patients but not those with other small- and medium-sized vessel vasculitides recognize multiple endothelial cell antigens. Clin Immunol 2003; 109:165-78.

22. Tong F, Lian Y, He F. Novel S-MSPQC cell sensor for real time monitoring the injury of endothelial cell by LPS and assessing the 
drug effect on this injury. Biosens Bioelectron 2015; 71:62-7.

23. Wosikowski K, Kung W, Hasmann M, Loser R, Eppenberger U. Inhibition of growth-factor-activated proliferation by anti-estrogens and effects on early gene expression of MCF-7 cells. Int J Cancer 1993; 53:290-7.

24. Beauchamp C, Fridovich I. Superoxide dismutase: improved assays and an assay applicable to acrylamide gels. Anal Biochem 1971; 44:276-87.

25. Zollner S, Aberle S, Harvey SE, Polokoff MA, Rubanyi GM. Changes of endothelial nitric oxide synthase level and activity during endothelial cell proliferation. Endothelium 2000; 7:169-84.

26. Xue L, Xu F, Meng L, Wei S, Wang J, Hao P, et al. Acetylationdependent regulation of mitochondrial ALDH2 activation by SIRT3 mediates acute ethanol-induced eNOS activation. FEBS Lett 2012; 586:137-42.

27. Munzel T, Daiber A, Ullrich V, Mulsch A. Vascular consequences of endothelial nitric oxide synthase uncoupling for the activity and expression of the soluble guanylyl cyclase and the cGMP-dependent protein kinase. Arterioscler Thromb Vasc Biol 2005; 25:1551-7.

28. Crabtree MJ, Tatham AL, Hale AB, Alp NJ, Channon KM. Critical role for tetrahydrobiopterin recycling by dihydrofolate reductase in regulation of endothelial nitric-oxide synthase coupling: relative importance of the de novo biopterin synthesis versus salvage pathways. J Biol Chem 2009; 284:28128-36.

29. Nurkiewicz TR, Wu G, Li P, Boegehold MA. Decreased arteriolar tetrahydrobiopterin is linked to superoxide generation from nitric oxide synthase in mice fed high salt. Microcirculation 2010; 17:14757.

30. Masano T, Kawashima S, Toh R, Satomi-Kobayashi S, Shinohara M, Takaya T, et al. Beneficial effects of exogenous tetrahydrobiopterin on left ventricular remodeling after myocardial infarction in rats: the possible role of oxidative stress caused by uncoupled endothelial nitric oxide synthase. Circ J 2008; 72:1512-9.

31. Rochette L, Lorin J, Zeller M, Guilland JC, Lorgis L, Cottin Y, et al. Nitric oxide synthase inhibition and oxidative stress in cardiovascular diseases: possible therapeutic targets? Pharmacol Ther 2013; 140:239-57.

32. Ming XF, Barandier C, Viswambharan H, Kwak BR, Mach F, Mazzolai L, et al. Thrombin stimulates human endothelial arginase enzymatic activity via RhoA/ROCK pathway: implications for atherosclerotic endothelial dysfunction. Circulation 2004; 110:3708-14. 33. Pope AJ, Karuppiah K, Cardounel AJ. Role of the PRMTDDAH-ADMA axis in the regulation of endothelial nitric oxide production. Pharmacol Res 2009; 60:461-5. 